\title{
O CÓDIGO CIVIL, A GLOBALIZAÇÃO E OS NOVOS CONTORNOS DO DIREITO PRIVADO ${ }^{1}$
}

\author{
THE CIVIL CODE, GLOBALIZATION AND THE NEW OUTLINES OF THE PRIVATE LAW
}

\section{Alberto do Amaral Junior}

Resumo:

Este artigo investiga como os efeitos da globalização operam sobre o Código Civil, assim como o modo em que ela reverbera sobre o direito privado. $\mathrm{O}$ tema será analisado a partir da experiência brasileira, com destaque às particularidades evidenciadas em um país em desenvolvimento, diferenciando-se da forma em que se apresenta nos países europeus. O estudo busca apontar como o fenômeno da globalização contribui para a experiência de organizar o direito privado em códigos, de forma a colaborar para a solução adequada dos conflitos sociais.

Palavras-chave: Civil de 1916. Direito privado. Globalização.

\begin{abstract}
:
This paper investigates how the globalization effects works on the Civil Code and on the Private Law as well. The theme will be analyzed under the Brazilian experience, highlighting the particularities of a developing country, differentiating from the way it presents itself on Western Europe. The study aims on how the globalization phenomenon contributed for the experience of organizing Private Law in codes, in a way to help finding a proper solution for social conflict.
\end{abstract}

Keywords: Brazilian 1916 Civil Code. Private Law. Globalization.

Introdução

O presente artigo nasceu a partir de uma inquietante pergunta: qual é o efeito da globalização sobre o Código Civil e, de modo mais amplo, sobre o direito privado?

Naturalmente, como é fácil notar, a tentativa de responder a esta indagação requer delimitações prévias, sem as quais o fracasso se mostra inevitável. Meu propósito é, nesse sentido, analisar o tema à luz da experiência brasileira, tendo como pano de fundo a celebração, em 2016, do centenário do nosso primeiro Código Civil. Referido limite é importante porque realça, desde logo, a especificidade de um país em desenvolvimento, cujas características não correspondem às encontradas nos países europeus onde a moderna codificação do direito privado começou. Seria inconcebível ignorar, para fins analíticos,

Texto elaborado em razão do Colóquio "Cem Anos de Codificação Civil Brasileira", realizado na Faculdade de Direito da Universidade de São Paulo no mês de agosto de 2016.

* Professor Associado do Departamento de Direito Internacional Comparado da Faculdade de Direito da Universidade de São Paulo. 
a força impregnante da codificação nas nações pertencentes à família romano-germânica. Não desejo, por outro lado, explorar em minúcia o enorme impacto que a globalização exerceu sobre a redefinição dos conceitos jurídicos tradicionais. Procuro apontar, tão somente, de forma menos ambiciosa, alguns efeitos da globalização para experiência de organizar o direito privado em códigos que, supostamente, deveriam fornecer a solução adequada para os conflitos sociais. Adianto que usarei o termo globalização para designar um processo social, marcado por relações de presença e ausência, pelo alongamento das relações humanas ao redor do mundo, graças à revolução das comunicações que comprimiu o espaço e o tempo. Valho-me, na abordagem a seguir empreendida, de algumas dicotomias utilizadas para ajudar a esclarecer o sentido e o alcance das transformações que pretendo focalizar.

O Código Civil e as mudanças sociais

O movimento codificador nos países vinculados à tradição jurídica romanogermânica tem natureza histórica e cultural. Surge no continente europeu, em fins do século XVIII e início do século XIX, e coincide com a consolidação do Estado moderno, a busca de superar os resquícios do feudalismo que ainda se mantinham intactos, por meio da supremacia do direito de origem estatal. A força do Iluminismo dominante valorizou a Razão para o conhecimento da realidade com o resultado de que, no plano jurídico, a sistematização e a coerência tiveram especial relevo. Os códigos, ademais, ao contrário das consolidações, não se ocupavam, simplesmente, em adaptar morfologicamente os institutos e regras em um todo significativo. Instituíam novas normas que espelhavam os valores do liberalismo nascente. Os códigos no direito privado e as constituições no direito público cumpriram funções complementares. Cabia às constituições limitar a extensão do poder estatal, organizar a divisão dos poderes e a estrutura do Estado. Aos códigos reservou-se a tarefa de garantir a propriedade privada e a liberdade contratual, essenciais para o funcionamento do mercado.

O Código Civil brasileiro de 1916 é herdeiro direto do movimento codificador europeu. Os mesmos ideais que na Europa estimularam o aparecimento dos códigos modernos permitiram, no Brasil, a adoção do Código Civil de 1916. Especificidades históricas e sociais indiscutíveis distinguiram a codificação do direito civil entre nós. O Código entra em vigor duas décadas e meia após a proclamação da República e quase trinta anos depois da abolição da escravatura. Vale lembrar, a esse respeito, que os negros formalmente libertos em 1888 ingressaram no mercado de trabalho desprovidos dos requisitos indispensáveis para o exercício profissional com dignidade. Representavam, na verdade, um expressivo contingente humano que se viu condenado à 
pobreza e a marginalidade social, uma das causas da profunda desigualdade que afetou a organização da sociedade no curso do século XX e no limiar do século XXI.

A primeira Constituição republicana de 1891 e o Código Civil de 1916 desempenharam papel complementar relativamente à institucionalização da esfera pública e da esfera privada. Apesar disso, permanecia vivo o contraste em ambos os domínios entre o país formal e o país real. A institucionalização da esfera privada percorreu caminho lento e tortuoso numa sociedade agrária, que exportava bens primários, sobretudo o café. $\mathrm{O}$ Brasil moderno só desponta nos anos 30, no governo de Vargas, conhecido pelas mudanças introduzidas na estrutura do Estado, que viabilizariam as bases para o crescimento industrial em larga escala. Os anos 50 tiveram, na realidade, relevância crucial, pois assistiram à criação da Petrobras, do Banco Nacional de Desenvolvimento Econômico e Social, além do Plano de Metas posto em prática pelo governo JK. As décadas de 50 e 60 registram a alteração do papel do Estado, que se torna indutor do crescimento econômico. A concentração de renda, drasticamente agravada pela ditadura militar, enseja diferenças abissais com consequências para a articulação das esperas pública e privada.

As nações europeias industrializadas presenciaram o crescimento do Estado e das instâncias administrativas públicas tanto para corrigir os desequilíbrios do mercado quanto para promoverem o Estado do Bem-Estar Social, fundado no acordo tácito de classes e na transferência de riqueza aos setores mais pobres. No Brasil, diversamente, a expansão do Estado corresponde a uma ação deliberada para encorajar o desenvolvimento econômico numa clara inversão do que sucedeu nos países de capitalismo avançado.

O reflexo jurídico de tantas mudanças expressou-se no esmaecimento das fronteiras entre o direito público e o direito privado. Evidentemente, os fatores sociais que motivaram esse fenômeno diferem na Europa e no Brasil. No primeiro caso, o liberalismo clássico, confundido com o Estado mínimo, incumbido de manter a integração da sociedade por meio de regras gerais e abstratas, cedeu lugar, ao menos na Europa ocidental, ao Welfare State, fundado no predomínio de uma lógica finalística, que visa a assegurar os direitos sociais enquanto crédito aos frutos acumulados pelo crescimento econômico ao longo do tempo. No Brasil, em contraste, coube ao Estado induzir a passagem da sociedade agrária, existente até os anos 30, para a sociedade industrial sem que houvesse compromisso com a distribuição dos recursos advindos desse processo. Apesar de partirem de contextos distintos, a publicização do direito privado e a privatização do direito público tiveram, sob o prisma formal, resultados similares, mas grandemente variou o produto e o impacto desse fenômeno. Vistas as coisas sob o ângulo formal, a intervenção do Estado brasileiro no domínio econômico provocou alterações consideráveis nos dois institutos centrais do direito privado, a saber, a propriedade e o contrato. Analogamente, a privatização do direito público propiciou, pelo Estado, o intenso uso de regras privadas, seja na esfera dos contratos, seja na constituição de empresas estatais. Enquanto o Welfare State proporcionou 
a formação de uma extensa classe média, no Brasil o governo assumiu custos que, a rigor, recairiam sobre o setor privado. É nítido, ademais, o modo pelo qual as vantagens geradas pela modernização econômica foram desigualmente repartidas, causa direta de discrepâncias sociais profundas que marcaram e ainda marcam a vida social no Brasil. A rápida urbanização, que transferiu do campo para as cidades parcela considerável da população brasileira, a instalação no país de indústrias estrangeiras e o fortalecimento do empresariado nacional graças ao programa de substituição de importações, o subsequente avanço do comércio de serviços, principalmente entre 1980 e 1990, repercutiram sobre a capacidade do Código Civil para disciplinar as relações individuais. Conjugadas, tais razões levam à crise da codificação civil e, por conseguinte, ao ideário que lhe serviu de base.

Aponto, muito brevemente, três delas, sem a pretensão de exclusividade. Refiro-me às crises de legitimidade, de integração e de hegemonia, cujos traços essenciais tento sintetizar:

1. crise de legitimidade. O Código Civil estipulou regras para sujeitos presumidamente iguais em uma sociedade extremamente desigual, que assistiu, com o decorrer do tempo, a ampliação das diferenças econômicas entre os grupos e classes que a constituíam. O conceito de sujeito de direito, que tem na vontade livre o seu traço mais eloquente, serviu para neutralizar as diferenças de toda ordem, de tal sorte que tudo se resumia no cumprimento das condições formais para contratar. Indivíduos poderosos e destituídos de poder, ricos e pobres, sábios e ignorantes eram, dessa forma, artificialmente equiparados. A organização dos interesses em grupos e segmentos específicos, locatários, consumidores, movimentos que apregoavam a reforma do direito de família e do direito de propriedade, não percebiam o Código como o espelho dos seus mais caros interesses. Mesmo se abstrairmos a materialidade das reivindicações em jogo, o Código, entendido como procedimento para disciplinar as relações interindividuais, mostra-se cada vez mais incapaz para regular uma sociedade que se tornou complexa. Ele, pouco a pouco, é substantivamente esvaziado pela edição de leis destinadas a regularem situações particulares.

2. Crise de integração. O Código de 1916, à semelhança dos grandes códigos do século XIX, teve a função de integrar o direito privado porque reunia, em um documento único, as normas fundamentais para a vida cotidiana dos indivíduos. Havia, na origem do movimento codificador, inequívoca correspondência entre o papel integrador do Estado, a quem cabia superar a fragmentação política medieval, e a função reservada ao Código, 
de expressão da supremacia das fontes jurídicas estatais. É justamente quando amplia, quase sem cessar, o esvaziamento do Código mediante a edição de leis especiais, que a crise de integração ganha densidade, a ponto de deslocar a regulação do Código para as leis que se ocupam de temas e assuntos que mobilizaram o interesse dos codificadores. Decorrência natural desse cenário, formam-se, no campo privado, subsistemas normativos com lógicas próprias e princípios autônomos, que nem sempre terão uma harmoniosa convivência com o Código. Mais frequente, por esse motivo, é a colisão entre normas e valores que participam de subsistemas diversos, com fundados riscos para a integridade e credibilidade do direito privado. O Código, premido por alterações substanciais na esfera privada, é levado a abdicar a função integradora que antes possuía e que lhe outorgava a capacidade de harmonização do significado normativo. O regime jurídico da propriedade agrária, que exibe inequívoco sentido distributivo, afasta-se da disciplina mais estrita que o Código Civil outorgou à propriedade. Com as nuances que lhes são próprias, a propriedade urbana, no que concerne ao direito de construir, conhece limitações que se distanciam da formulação original do direito de propriedade previsto no Código Civil. A legislação especial admitiu, explicitamente, que divergem o regime jurídico aplicável aos bens de consumo e aquele que preside a propriedade de ações que conferem o poder de controle em uma grande sociedade anônima.

$\mathrm{O}$ direito contratual testemunhou, também, grande movimento de fragmentação perceptível em vasta quantidade de situações, tais como os contratos "presentificadores", os contratos cativos e de longa duração, os contratos que reúnem partes vulneráveis ou hipervulneráveis, os contratos internacionais de compra e venda de bens e os contratos plurilaterais que justapõem interesses para alcançarem um fim comum.

3. Crise de hegemonia. O Código Civil brasileiro e o movimento codificador do qual é caudatário expressam a consolidação do Estado moderno, a superação dos particularismos medievais no continente europeu, a variedade das leis civis, os valores do Iluminismo e a intenção de ser o instrumento legislativo fundamental a regular a esfera privada. Aparece, nessa acepção, na qualidade de veículo da supremacia estatal em face dos demais centros de poder estatal. A preeminência que ocupa é incontestável e as esparsas leis eventualmente aprovadas pelo Congresso, nos anos subsequentes à adoção do Código Civil, giram em torno dele e desdobram ou elucidam, quando muito, matérias previamente reguladas. A revolta dos fatos contra os códigos, assim qualificado o envelhecimento do Código Civil 
francês produzido pelas mudanças sociais, veio, guardadas as proporções, a ter lugar no Brasil com as transformações deflagradas a partir do primeiro governo Vargas e acentuadas nas décadas seguintes, notadamente no final dos anos 50, época que JK governou o país. A sucessiva edição de normas para satisfazer à multiplicidade dos interesses de uma sociedade que, economicamente, depressa se modernizou, concorreu, em larga escala, para o esvaziamento do Código Civil. A expansão do direito voltado para abarcar reivindicações de justiça material, opunha-se, frontalmente, ao rígido formalismo do Código Civil, espelho das aspirações da sociedade brasileira de fins do século XIX, cuja pauta de exportações destacava os bens primários.

O Código de Defesa do Consumidor, que passou a vigorar em março de 1991, esboça, com clareza meridiana, a crise do Código Civil. Com base na ideia de ordem pública de proteção, que visou salvaguardar os interesses do consumidor, tido como a parte vulnerável das relações de consumo, o Código inspirou-se na ideia de microssistema normativo, sem a abrangência dos ideais que marcaram o Código Civil. Assuntos tão diferentes quanto a responsabilidade pelo fato do produto e do serviço, dos vícios de qualidade e quantidade, a disciplina da publicidade enganosa e abusiva, a tutela administrativa, criminal e processual foram simetricamente justapostas sob o comando de um vetor axiológico comum. Enquanto o Código Civil instituiu regras para relações entre iguais, o Código de Defesa do Consumidor pretendeu, sem rodeios, dar prioridade às regras entre desiguais, que congregam os que são técnica, econômica e juridicamente vulneráveis no mercado de consumo. Prova eminente da perseguição de uma justiça material, o Código de Defesa do Consumidor ditou nova regra hermenêutica no domínio contratual. Em todos os casos e não apenas se houver dúvida ou obscuridade, as regras serão interpretadas em benefício dos consumidores.

O Código Civil de 2002 tenta, nostalgicamente, recuperar a centralidade perdida, mas é inevitável reconhecer que esta tentativa estava, desde logo, condenada ao fracasso. É verdade que o novo Código Civil deu primazia às cláusulas gerais com o escopo de lidar com a extraordinária velocidade das mudanças sociais. A concepção que o informa, entretanto, advinda do movimento codificador, mostra-se incapaz de reduzir à pluralidade social à unidade do código. Expostas as crises a que o Código Civil mergulhou, seja na versão de 1916, seja na versão de 2002, cabe agora investigar com maior atenção quão relevantes são os acontecimentos externos para redefinir o direito privado no Brasil. 
O Código Civil em um mundo globalizado

Três episódios registraram, no final do século passado, a integração do Brasil no cenário econômico global: a abertura às exportações levada a cabo no início dos anos 90, a celebração do Tratado de Assunção, que criou o Mercosul em março de 1991 e a participação na Rodada Uruguai que criou a Organização Mundial do Comércio. Tratados que versam o comércio de bens, o comércio de serviços e dos direitos de propriedade intelectual ratificados pelo governo brasileiro foram, como se exige, incorporados ao direito interno. À publicização do direito privado e a privatização do direito público, oportunamente comentadas, sobrepõem-se agora o obscurecimento das fronteiras a separar o direito internacional e o direito doméstico tanto quanto o direito internacional público e o direito internacional privado. Já conhecidos em países de capitalismo maduro, tais fatos concorreram decisivamente para reconfigurar o direito privado brasileiro. Evidentemente, fenômenos de tamanha grandeza contaram com a força de uma dinâmica social transnacionalizada, que revelou, com pesos diferentes, a participação das organizações internacionais e não governamentais, de associações de natureza mista e de corporações que atuam em nível global. A fim de averiguar o impacto desse processo sobre o Código Civil, em particular, e sobre a conformação do direito privado em geral, usarei, como recurso analítico, algumas dicotomias que podem iluminar importantes aspectos do tema que ora me ocupo:

1. unidade e pluralismo. O Código consagra, na era moderna, não apenas os valores do liberalismo nascente mas também o triunfo da unidade do direito privado. Supera, desse modo, a ausência de hierarquia entre as fontes do direito que prevaleceu durante a Idade Média. O longo caminho para suplantar o pluralismo político e jurídico medieval levou à consolidação do Estado moderno, simbolizada pela Paz de Westfália, que pôs fim às guerras religiosas no continente europeu. A proeminência das fontes jurídicas estatais sobre o costume e a doutrina, que anteriormente não existia, é um fato novo, de enorme significado, pródigo em sinais reveladores dos novos tempos. Característica intrínseca à soberania, o poder político funda-se na exclusividade do uso da força, em oposição ao poder econômico, baseado na propriedade dos bens materiais e do poder ideológico, que cuida da posse e administração dos bens espirituais. $\mathrm{O}$ direito obriga, nessa conjuntura, em virtude de regular o uso da força, conforme uma de suas mais refinadas definições, em nítido contraste com a religião, a moral e as regras de etiqueta. A coerção sublinha a especificidade do direito quando comparado com as demais formas de normatividade. As fontes jurídicas formais são, 
pois, identificadas aos atos e processos criadores de normas vinculantes para os destinatários. É óbvio que, à luz da divisão dos poderes, a lei emanada do parlamento é a fonte jurídica por excelência. A reestruturação das funções do Estado no século XX e a realidade propiciada pela globalização deram origem à pluralidade das fontes do direito. Decretos, resoluções, circulares e portarias desafiam a todo o momento a supremacia da lei, instauram cadeias normativas que nem sempre encontram na Constituição a fonte comum de validade. O Código Civil, espelho inconteste da unidade normativa privada, viu-se às voltas com regras hierarquicamente inferiores capazes de definirem, concretamente, o alcance dos direitos e obrigações já estipulados.

2. Fontes formais e fontes informais. Nos últimos decênios do século passado, ganharam destaque, pelo volume e extensão que vieram a manifestar-se, realidades já conhecidas e outras indicativas de grande novidade. Refiro-me às fontes jurídicas informais, designadas por soft law na terminologia do direito internacional. Essa denominação prestava-se, acima de tudo, a uma finalidade essencial: opor o informalismo do soft law à formalidade das fontes convencionais. A doutrina distinguia e de certo modo ainda distingue as fontes formais, dotadas de obrigatoriedade, das fontes informais, que simplesmente apelam aos governos, corporações e indivíduos para adotarem os comportamentos recomendados. A classificação entre hard e soft law repousa entre regras de cumprimento obrigatório e meras recomendações, que podem ou não serem seguidas por todos aqueles a quem são dirigidas. Parece enganar-se, todavia, a doutrina quando efetua a separação binária entre o jurídico e o não jurídico levando em conta, tão somente, a regulação do uso da força. O uso ampliado do soft law no direito doméstico e no direito internacional aliada crescentemente ao convencimento que passou a exercer anula a radicalidade da divisão forjada pela doutrina. Muito mais adequado é vislumbrar uma continuidade e entre o hard e o soft law, de sorte que ambos desempenham, ainda que diferentemente, papéis complementares na experiência jurídica. Por essa razão, as regras de soft law são "fontes de baixa intensidade", que preenchem lacunas, antecipam o direito futuro e desfrutam de capacidade persuasiva a ponto de motivarem as condutas pretendidas. No terreno econômico propriamente dito, os chamados "padrões privados" estabelecem o que se deve comprar, vender e consumir moldando o comportamento dos agentes no interior do mercado. A proibição requerida por organizações não governamentais localizadas em países desenvolvidos de importar mogno da 
região amazônica, oriundo da dilapidação da floresta, a recomendação para que os consumidores se abstenham de consumir produtos que utilizam a madeira tropical, como o papel, a fixação de critérios para a comercialização de carne bovina resultante de rebanhos situados em áreas desflorestadas, as campanhas para que não se adquiram produtos nocivos ao meio ambiente, devido à existência de normas elaboradas nesse sentido, corroboram e reafirmam a influência do soft law e, por assim dizer, das fontes jurídicas informais nas atitudes dos indivíduos e empresas.

3. Regulação pública e regulação privada. O domínio privado é intensamente recortado por normas de variada procedência. Organizações internacionais e não governamentais, organizações privadas e de natureza mista, tornaram-se instâncias normativas independentemente das limitações físicas representadas pelas fronteiras nacionais. O Fundo Monetário Internacional, o Banco Mundial, a Organização Mundial do Comércio, a Organização Internacional de Padronização, além de inúmeras associações privadas que se dedicam a proteger o meio ambiente e os direitos humanos ao redor do mundo regulam, em escala inusitada, a conduta dos diversos sujeitos jurídicos. Camadas regulatórias superpostas definem e redefinem o domínio privado, no qual a centralidade do Código Civil declina a olhos vistos em meio às regras nascidas de um sem-número de fontes nacionais, regionais e globais. É patente, nessa ordem de ideias, o esfacelamento da rígida divisão entre o direito público e o direito privado interno e internacional. Interesses privados de corporações transnacionais permeiam, muitas vezes, a formulação de políticas públicas e interesses sociais de natureza global são defendidos por organizações não governamentais que, em não poucas ocasiões, são porta-vozes do protecionismo das nações desenvolvidas.

4. Alta e baixa interatividade. A centralidade do Código Civil traduziuse nas escassas relações que manteve com outros ramos do direito. A legislação que o circundava era, quando muito diminuta, preparada para complementar-lhe aspectos circunstanciais. Por algum tempo não afetaram nem mesmo chegaram a comprometer a hegemonia que ocupou. Esta situação tende a mudar nos decênios seguintes, primeiro com maior lentidão e depois impelida pelas demandas de justiça material na órbita doméstica e pela inserção do país na economia globalizada. As interações avolumaram-se seja com a legislação civil, que conquistou autonomia perante o Código, seja com as normas, entre outros, vinculadas ao direito 
comercial, administrativo, financeiro e processual. A interpretação do direito privado à luz da Constituição, que, por longo período, foi raramente invocada, chegou, por influência estrangeira, notadamente alemã, à jurisprudência dos tribunais. O Código de Defesa do Consumidor interagiu e continua a interagir com o Código Civil. Nos anos que se seguiram à aprovação do Código de Defesa do Consumidor, juízes e tribunais lançaram mão da boa-fé objetiva para julgar litígios civis. O Código Civil de 2002 não deixou de aludir às regras mercantis nos dispositivos dedicados às sociedades. A alta interação é perceptível, também, quando pelo "diálogo das fontes" duas ou mais normas são ao mesmo tempo aplicadas. As relações entre o Código Civil de 2002 e o Código de Defesa do Consumidor mostram claramente a fertilidade desse "diálogo." Por serem material e axiologicamente incompletas, as regras sobre direito de família inscritas no Código Civil, impõem ao intérprete a inevitável missão de completálas recorrendo ao texto constitucional e mesmo às leis ordinárias que com elas se relacionam. A mera aquisição de um imóvel comporta a aplicação de normas simultâneas que podem, inclusive, limitar o alcance do direito de propriedade reconhecido pelo Código Civil. Leis urbanas, movidas pela necessidade de ocupação racional do solo nas cidades, restringem, em certas áreas, o direito de construir, impõem a criação de reservas vegetais ou limitam a edificação em zonas próximas aos mananciais de água potável.

5. Regulação rasa e regulação profunda. Estas expressões, convém lembrar, não são valorativas empregadas para qualificar positiva ou negativamente dada situação. Meu propósito, ao contrário, é simplesmente descritivo indicando a extensão do campo regulatório. São rasas as regulações que se originam no Estado nacional e confundem-se com os limites geográficos das fronteiras que os separam dos demais Estados. A regulação profunda, tenha ela natureza formal ou informal, deriva de organizações internacionais e não governamentais, que operam em escala regional ou universal. Grandes corporações, com presença em diversos continentes, convertem-se em polos normativos, que predispõem cláusulas destinadas a produzir efeitos em muitas localidades do globo. No direito internacional, o Conselho de Segurança das Nações Unidas, no caso de ameaça à paz, ruptura da paz ou ato de agressão, tem a faculdade de decretar embargos econômicos que vinculam, indistintamente, o setor público e as empresas privadas dos países-membros da ONU. 
6. Direito "sólido" e direito "líquido". O direito "sólido", em minha opinião, contém subsistemas que raramente se comunicam. O Código Civil exemplifica o direito "sólido" pois organiza de maneira coerente um sistema de normas, presumidamente hermético, no qual o juiz deve buscar solução para os conflitos sociais. O pretenso hermetismo do Código deu lugar, com o curso do tempo, à porosidade a sugerir mútua influência entre os subsistemas jurídicos. A completude encontrou limite, ainda, no hiato aberto entre a rigidez das normas e a vertiginosa rapidez das mudanças históricas. Na condição de redutor da complexidade social a hipóteses normativas anteriormente elaboradas, o Código teve êxito apenas em curto período e logo viu-se despojado do papel que almejava exercer. O direito "líquido", por outro lado, espalha-se rapidamente e rapidamente "mergulha" em outros subsistemas normativos. Ninguém contesta, certamente, que os direitos humanos consagrados pela Constituição Federal e pelos tratados ratificados pelo Brasil irradiam efeitos que atingem a totalidade do direito público e do direito privado.

7. Direito "claro" e direito "escuro". Alude o direito "claro" à luz lançada pelas regras jurídicas a determinados fatos tornando-os visíveis a quem irá interpretá-los. Mesmo admitindo que a clareza é atributo da interpretação, é forçoso reconhecer que gozam de razoável dose de clareza as regras do Código Civil que disciplinam a competência dos administradores das sociedades ali reguladas, ainda que pairem dúvidas sobre a real extensão de dita competência. O direito "escuro" confunde-se com a pluralidade de normas que regulam os mesmos fatos e impedem contemplar um problema à luz de um conjunto claramente definido de normas. Uma grande corporação que exporte resíduos tóxicos pode estar, simultaneamente, sujeita a normas internas públicas e privadas bem como a normas internacionais sobre comércio e proteção ambiental.

8. Interesses contingentes e interesses robustos. Interesses contingentes são os que, na esfera econômica, consumam-se, de imediato com a realização das trocas. Contratos de compra e venda cujas prestações instantaneamente se concretizam demonstram a descontinuidade das trocas entre os agentes do mercado. Denomino interesses robustos os relativos à justiça intra e intergeracional ilustrada pela proteção dos direitos humanos e pela preservação do meio ambiente. No primeiro caso, afora o texto constitucional, que é o mais minucioso de nossa história republicana, o Brasil ratificou, no âmbito regional e universal, vasta gama de tratados 
relativos aos direitos humanos. Nesse rol estão aqueles que versam temas gerais, como o Pacto Internacional sobre Direitos Civis e Políticos e o Pacto Internacional sobre Direitos Econômicos, Sociais e Culturais, quanto os que abordam temas específicos, entre os quais se destacam a Convenção que proíbe a discriminação racial e contra a mulher, protege os direitos das crianças e das pessoas com deficiência. No tocante à preservação do meio ambiente, o Brasil é parte das grandes convenções internacionais sobre o tema, além de ter sediado, em 1992, a Conferência do Rio sobre Meio Ambiente e Desenvolvimento, que trouxe à baila a Convenção sobre Mudança do Clima, a Convenção sobre Diversidade Biológica, a Declaração do Rio sobre Meio Ambiente e Desenvolvimento, a Agenda 21 e a Declaração sobre Florestas. O Brasil é também signatário do Acordo de Paris, firmado em 2015, referente à mudança do clima, que substituiu o antigo Protocolo de Kioto. A Constituição de 1988, no art. 225, incorporou alguns dos mais importantes princípios internacionais, cristalizados por tratados internacionais na segunda metade do Século XX. Os interesses robustos corporificam limites éticos e naturais que o direito em geral e o direito civil em particular não podem ignorar.

São Paulo, agosto de 2016. 